\title{
THE MARX MODULATOR DEVELOPMENT PROGRAM FOR THE INTERNATIONAL LINEAR COLLIDER*
}

\author{
G.E. Leyh \\ Stanford Linear Accelerator Center \\ Menlo Park, CA 94025, USA \\ Email: leyh@slac.stanford.edu
}

\begin{abstract}
The ILC Marx Modulator Development Program at SLAC is working towards developing a full-scale ILC Marx 'Reference Design' modulator prototype, with the goal of significantly reducing the size and cost of the ILC modulator while improving overall modulator efficiency and availability. The ILC Reference Design prototype will provide a proof-ofconcept model to industry in advance of Phase II SBIR funding, and also allow operation of the new 10MW L-Band Klystron prototypes immediately upon their arrival at SLAC.
\end{abstract}

\section{INTRODUCTION}

The International Linear Collider [ILC] will require 576 ten-megawatt klystron stations. Each 10MW klystron will require $120 \mathrm{kV}, 140 \mathrm{~A}, 1500 \mathrm{usec}$ drive pulses, at a rate of $5 \mathrm{~Hz}$. The unusually long 1500usec pulse length requirement would adversely impact the size and cost of a transformer-driven modulator design, requiring tons of material in the transformer alone to support the volt-seconds of the pulse.

The ILC Marx Reference Design circumvents the need for a transformer through direct solid-state switching of capacitors, arranged in a Marx configuration. The reference design prototype also employs direct air-cooling of the power components, allowing the entire modulator to operate dry, without the need for high-voltage insulating oils.

\section{DESIGN OVERVIEW}

The baseline design for the ILC Marx modulator employs sixteen $12 \mathrm{kV}$ 'main' cells and sixteen 900V 'vernier' cells used for fine regulation of the output pulse. In normal operation, fourteen of the main cells are active, with two cells parked as spares. The parked cell locations continuously rotate, ensuring even wear time and confirming operational status for all components.

All sixteen of the vernier cells are active during normal operation, although the modulator can operate normally with as few as thirteen vernier cells. Figure 1 illustrates the mechanical arrangement of the steel backing frame, central modulator backbone, airflow apertures, modulator backplane and contoured support beams.

\section{A. Modulator Structural}

Three main components make up the structural framework of the modulator; the backing frame, the cantilevered backbone beam and the modulator backplane. The steel backing frame is a singular weldment that supports the cantilevered backbone and provides a firewall between the $12 \mathrm{kV}$ cells and the control circuitry. Two 19" control racks are built into the rear of the backing frame. Two air circulation units mount into the base of the control racks, with air intakes shown at (F) in Figure 1.

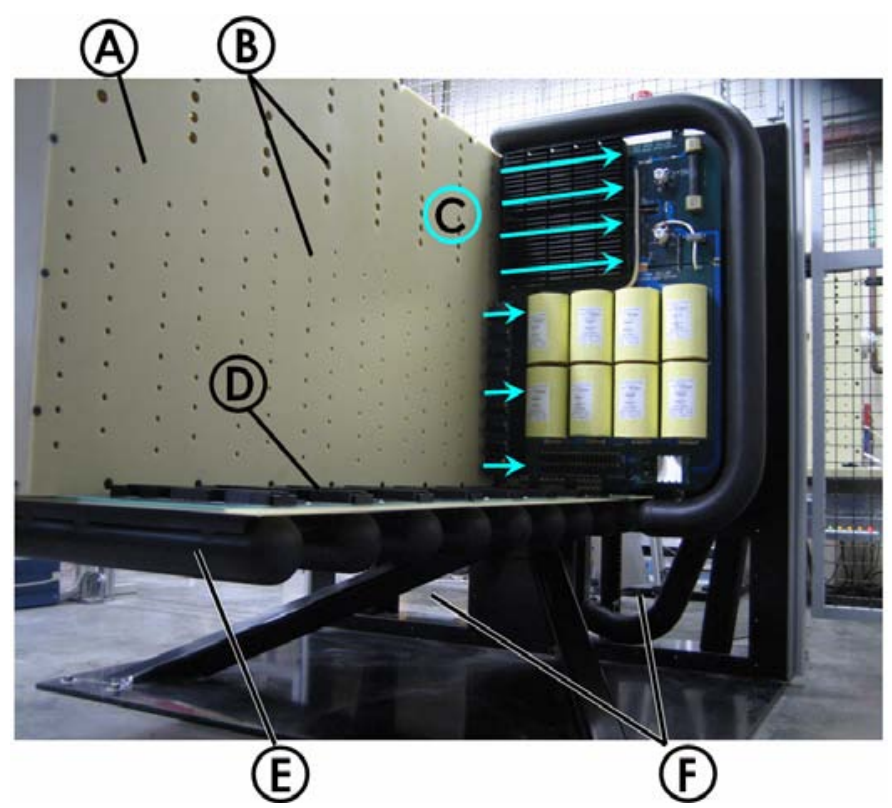

Figure 1. The Marx Modulator Prototype.

The cantilevered backbone beam indicated at (A) is essentially a G-10 hollow box beam, measuring $88 \mathrm{~cm}$ high by $10 \mathrm{~cm}$ wide. This beam supports all sixteen of the $12 \mathrm{kV}$ Marx cells, the vernier and charging regulators, and the modulator backplane (D). The beam is cantilevered from the grounded backing frame, eliminating the need for structural support members on the $120 \mathrm{kV}$ end between $\mathrm{HV}$ and ground. The beam is completely contained within the equipotential ring elements of the Marx cells, insuring that its surfaces see only low level, controlled electric fields.

Besides structural support, the cantilevered beam also provides several other key functions. The hollow interior of the beam serves as an air plenum, delivering forced-air to the Marx cells through strategically placed apertures located in the side panels, shown at (B). The forced air is directed across heat sinks on each cell, as shown at (C). 
The modulator backplane (D) in Figure 1 supports and locates the Marx cells, and provides the connectivity between them. Specially contoured tubular beams (E) are attached to the main cantilevered beam and support the backplane. These tube beams align with the equipotential rings of the cells, forming a continuous shield around the Marx cell components. Ansoft Maxwell 3D calculated the surface electric field contours on this equipotential ring system at $120 \mathrm{kV}$ operation. Figure 2 shows the results.

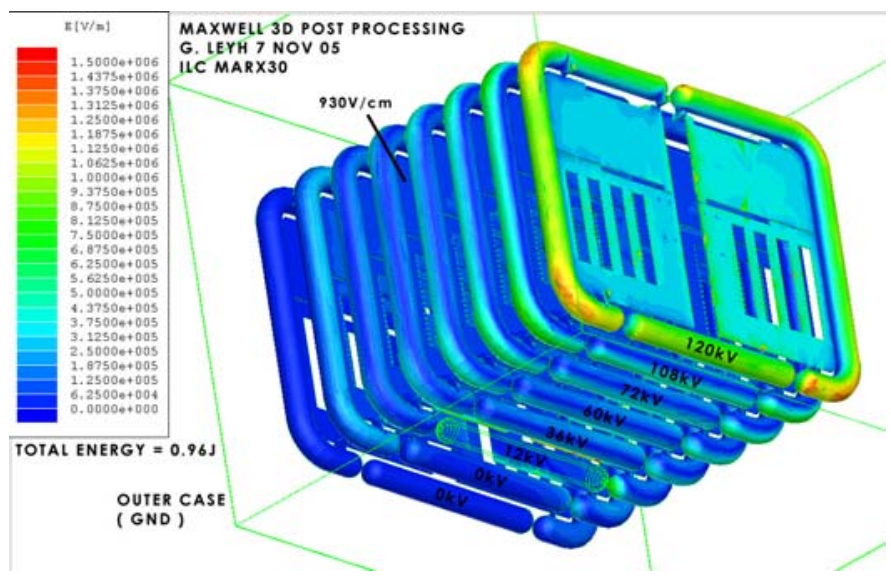

Figure 2. Surface electric fields at $120 \mathrm{kV}$.

The modulator backplane is made up of three large-scale PC boards, with PC-mount sockets and alignment bosses at each cell location as shown in Figure 3.

The alignment boss insures that the Marx cell is properly aligned before the cell can seat into the connectors (Figure 4).

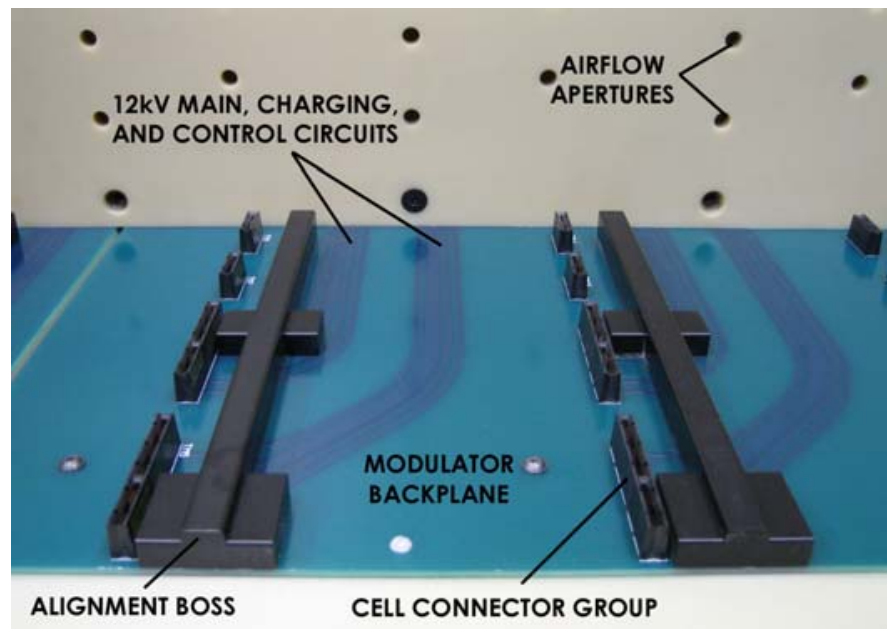

Figure 3. The Modulator Backplane.

Using a large-scale PC-board approach for the backplane, although expensive by normal PC-board standards, eliminates virtually all of the needs for $\mathrm{HV}$ hand-wiring and custom fixturing. This streamlines the assembly and QC processes, resulting in considerable cost savings.

\section{B. $12 k V$ Marx Cells}

The Marx cell uses a highly modular design approach, consisting of two large PC boards that provide connectivity between the all modular components of the cell. The two main PC boards mount to a support frame made up of delrin stiffeners connected to the aluminum equipotential ring that surrounds the cell. The equipotential ring, besides providing critical E-field shielding and mechanical rigidity, presents a well defined attachment point for robotic service platforms.

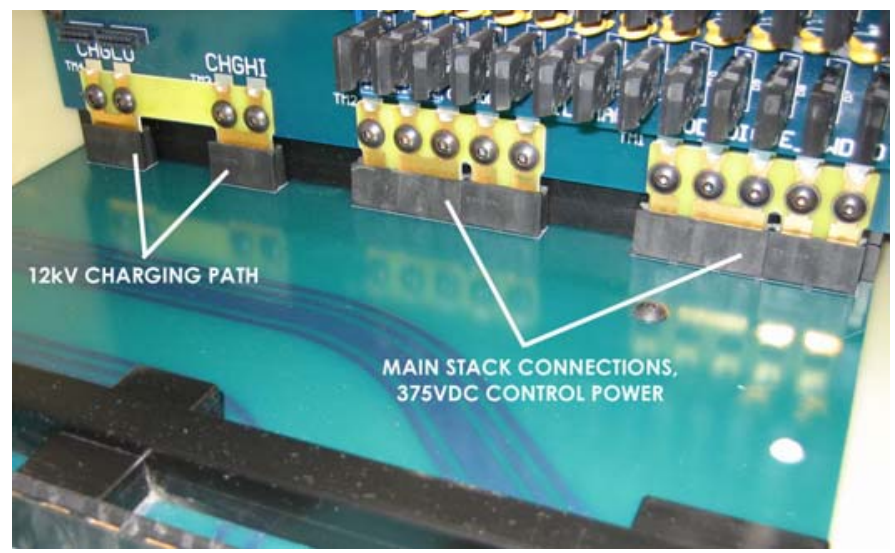

Figure 4. Marx Cell seated to Backplane.

A basic line diagram of the Marx cell showing the key components is illustrated in Figure 5. All of the diodes, switching elements and control boards are plug-in modules. The energy storage capacitors, discharge resistor and relays are mounted directly to the main PC boards.

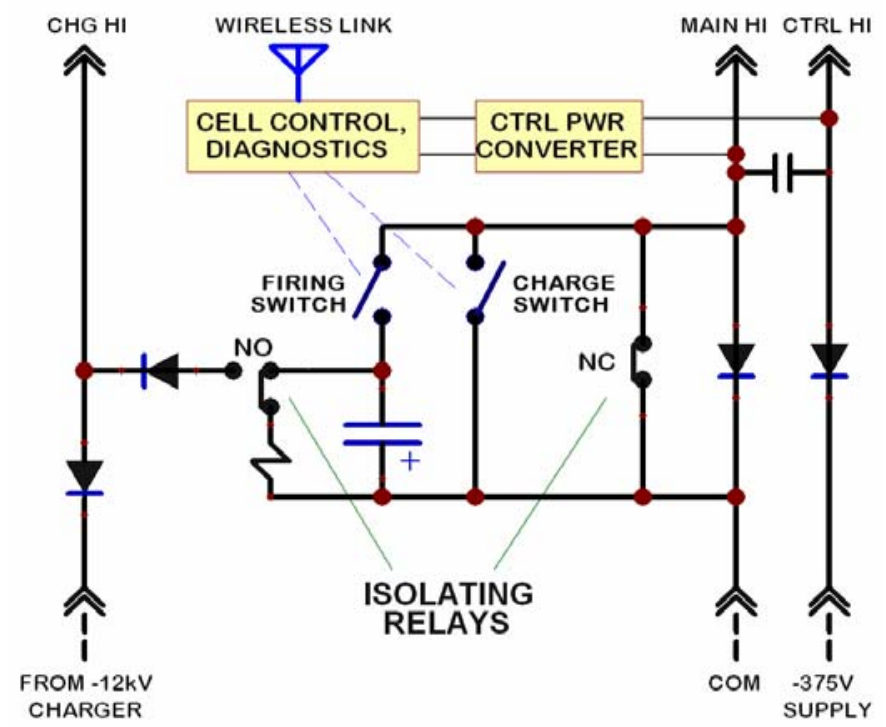

Figure 5. Marx Cell Line Diagram.

A $2.4 \mathrm{GHz}$ wireless communication link routes all control and timing signals to the cells, in order to provide the necessary $\mathrm{HV}$ isolation and to simplify robotic removal and installation of cells during maintenance operations. 
Figure 6 shows the mechanical layout of the $12 \mathrm{kV}$ Marx cell and placement of the key components. The charging and firing switches reside at locations (A) and (B), respectively. Each switch consists of five identical IGBT modules, each capable of supporting up to $3.2 \mathrm{kV}$, for a total switch holdoff capability of $17 \mathrm{kV}$. Each module has intrinsic over-voltage protection, and timing stabilization circuitry. The switch is designed to operate with one shorted module, at nominal $12 \mathrm{kV}$ operation. Each switch module is independently removable. The modules plug directly to the Marx cell as shown, and are held in place by two socket-head screws.

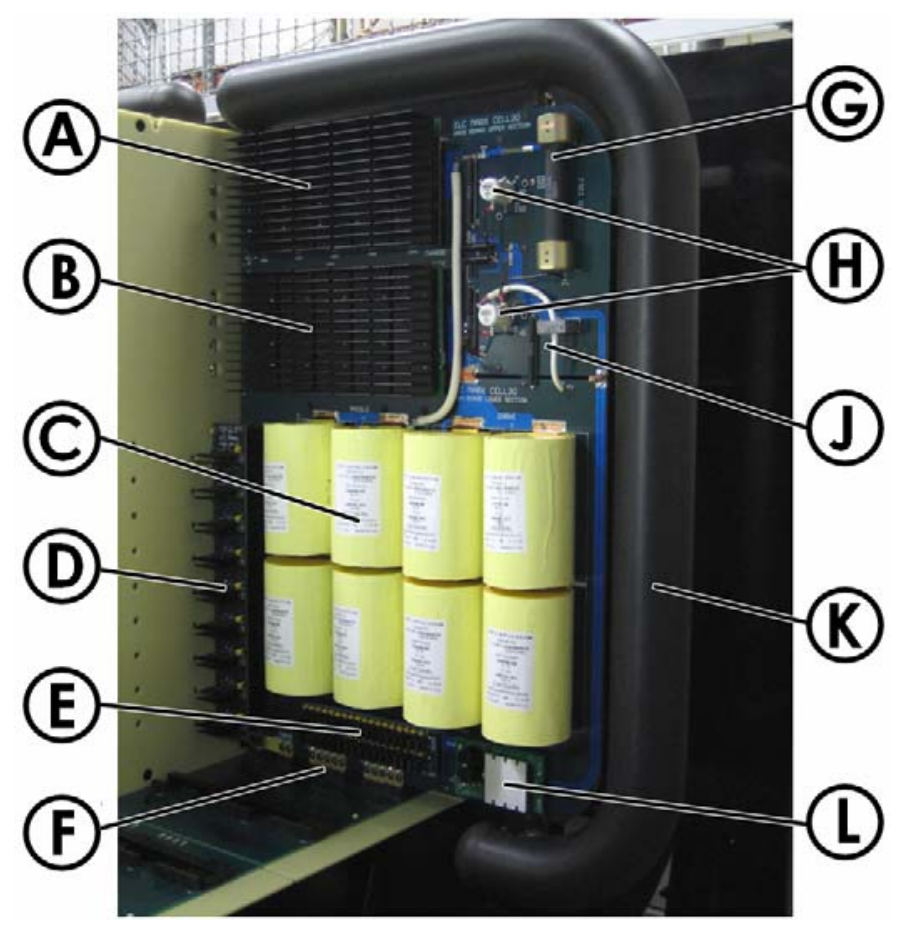

Figure 6. The $12 \mathrm{kV}$ Marx Cell.

The energy storage bank (C) consists of eight $96 \mathrm{uF}, 3 \mathrm{kV}$ capacitors arranged in series-parallel to obtain a total bank value of $48 \mathrm{uF}$ at $12 \mathrm{kV}$. Accelerated life testing of these individual capacitors at twice the rated voltage $(6 \mathrm{kV})$ and at nominal pulsed current predicts that at $3 \mathrm{kV}$ a service life of approximately 10e9 shots can be expected.

Both the charging diode module (D) and the cell-freewheel diode module (E) consist of eighteen APT60D100 diodes in series. Each diode element is bypassed by $100 \mathrm{pF}$ and $470 \mathrm{kOhm}$ to dynamically balance reverse voltages. The cellfreewheel module actually contains two diode stacks; the main freewheel diode and the $375 \mathrm{~V}$ blocking diode shown to the right in Figure 5. The charging diodes are mounted to heatsinks, located in the path of forced-air apertures on the cantilever beam.

The control power converter module $(\mathbf{L})$ steps down the unregulated 375VDC control power to a regulated 24VDC for local use by the vacuum relays and the control module. The converter must accept input voltages ranging from about $150 \mathrm{~V}$ to $375 \mathrm{~V}$ depending on its position in the Marx stack, owing to the forward voltage drop of the HV diodes.

Other components shown in Figure 6:

(F) Backplane connector group

(G) $2 \mathrm{kOhm}, 12 \mathrm{~kJ}$ discharge resistor

(H) Vacuum cell isolator relays

(J) Charging current monitor, HV dividers

(K) Equipotential ring

\section{PROTOTYPE TESTING}

As of the time of this writing, the first Marx cell prototype is complete and has been on the new test stand for about one week. The test stand and Marx cell are shown in Figure 7.

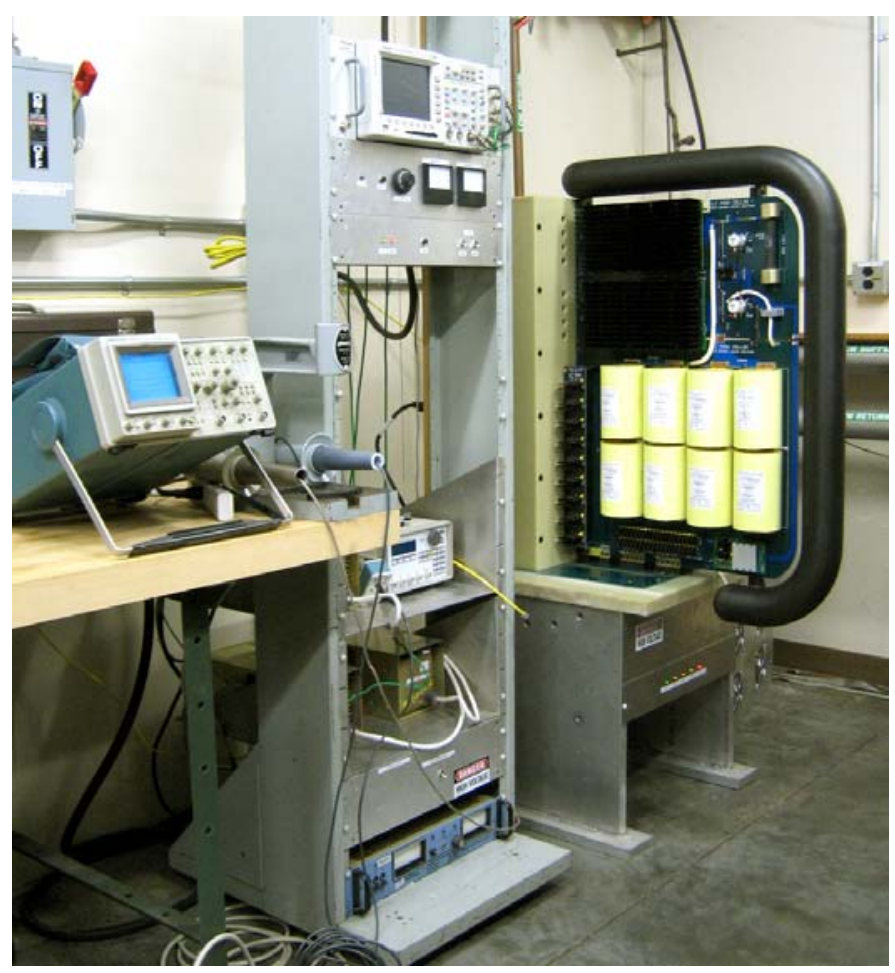

Figure 7. Marx Cell Test Stand.

The first week of testing has already uncovered several PC board routing errors, and component problems. The routing errors were minor, and quickly resolved with rework.

The vacuum relays, which had performed without incident during weeks of previous component testing, began to exhibit contact-to-ground faults. The manufacturer recommended using the next largest size, which appears to have fixed the problem for the time being. Further testing is required.

The overcurrent protection circuitry for the IGBT switches is designed to provide separate trip delay times at several overcurrent trip points. Under certain fault conditions the protection circuitry exhibited unpredictable trip delay times, possibly caused by noise pickup. A fundamental re-design of this circuit is presently in the works to address the problem. 
The test stand can operate a Marx cell at up to $12 \mathrm{kV}$ and $140 \mathrm{~A}$ at full pulse width, into an $88 \mathrm{ohm}$ air-cooled resistive load. Figure 8 shows the measured cell output voltage and current waveforms into the $88 \mathrm{ohm}$ test load. The green trace represents the output voltage, at $-3 \mathrm{kV}$ per division. The violet trace represents output current, at $100 \mathrm{~A}$ per division.

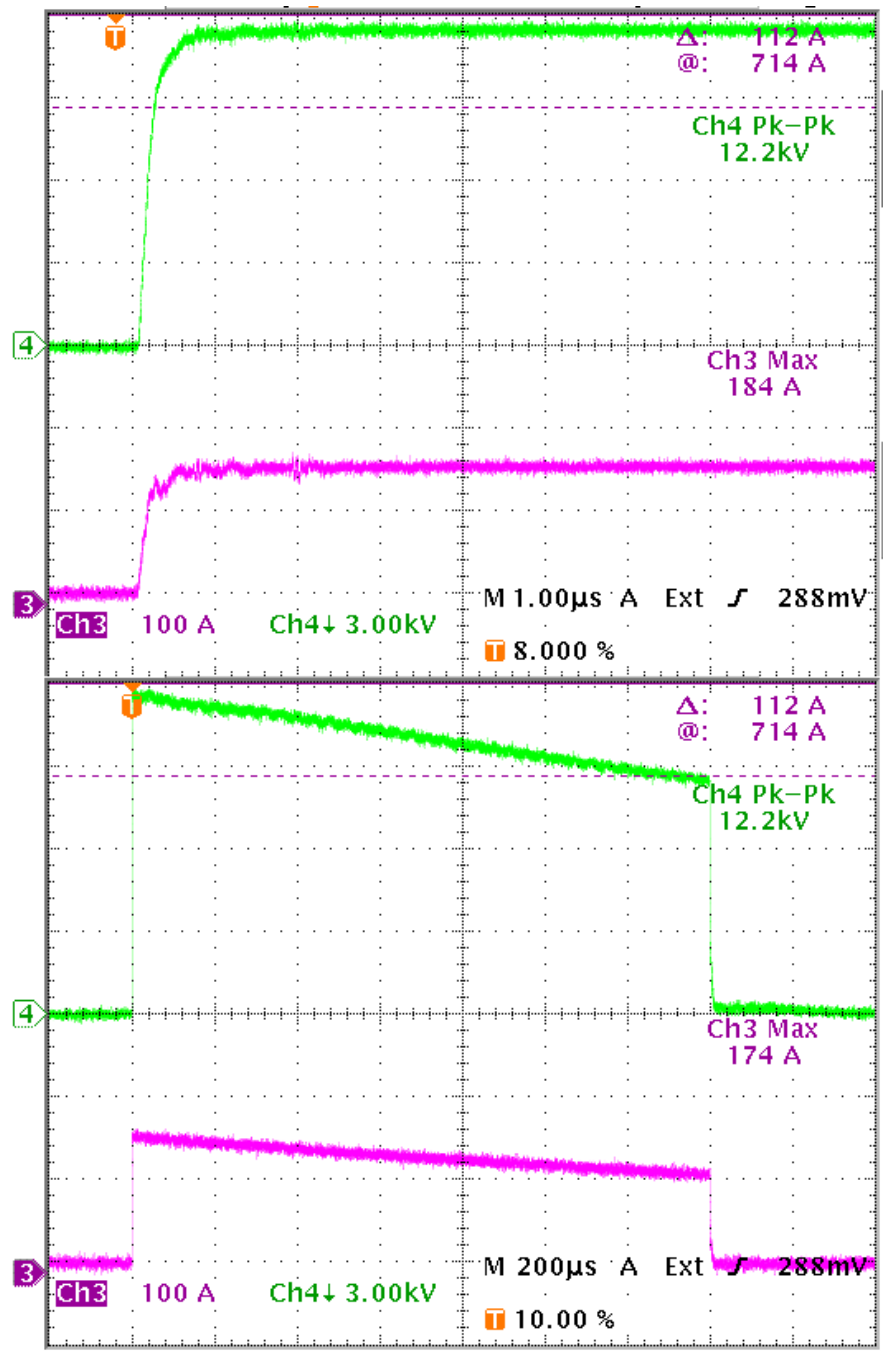

Figure 8. Marx Cell Test Waveforms.

The top screen shows the rise time of the Marx cell, at 1 usec per division. The rise time to $12 \mathrm{kV}$ is typically less than 0.5 usec. The lower screen shows the total 1400usec pulse, at 200usec per division. The capacitor droop of about $25 \%$ will be leveled by the delayed $12 \mathrm{kV}$ cells, operating in conjunction with the $900 \mathrm{~V}$ vernier cells in the actual modulator.

\section{PROJECT STATUS}

Most mechanical work is complete on the Marx modulator core structure. Remaining items include coaxial cable terminations, $120 \mathrm{kV}$ end cap shielding, the air heat exchanger / blower units and internal ducting. The first $12 \mathrm{kV}$ Marx cell is working on a conditional basis, but requires further study of the vacuum relay failures and the noise pickup in the overcurrent protection circuits.

The remaining fifteen Marx cells are now in production, minus the problematic components listed above. Testing multiple Marx cells on the actual modulator frame will begin ramping up as the cells are built and tested, and when the $150 \mathrm{~kW}$ air-cooled test load (Figure 9) is assembled and connected to the modulator. Operation with ten Marx cells producing a $120 \mathrm{kV}$ unregulated output pulse is expected sometime in August 2006.

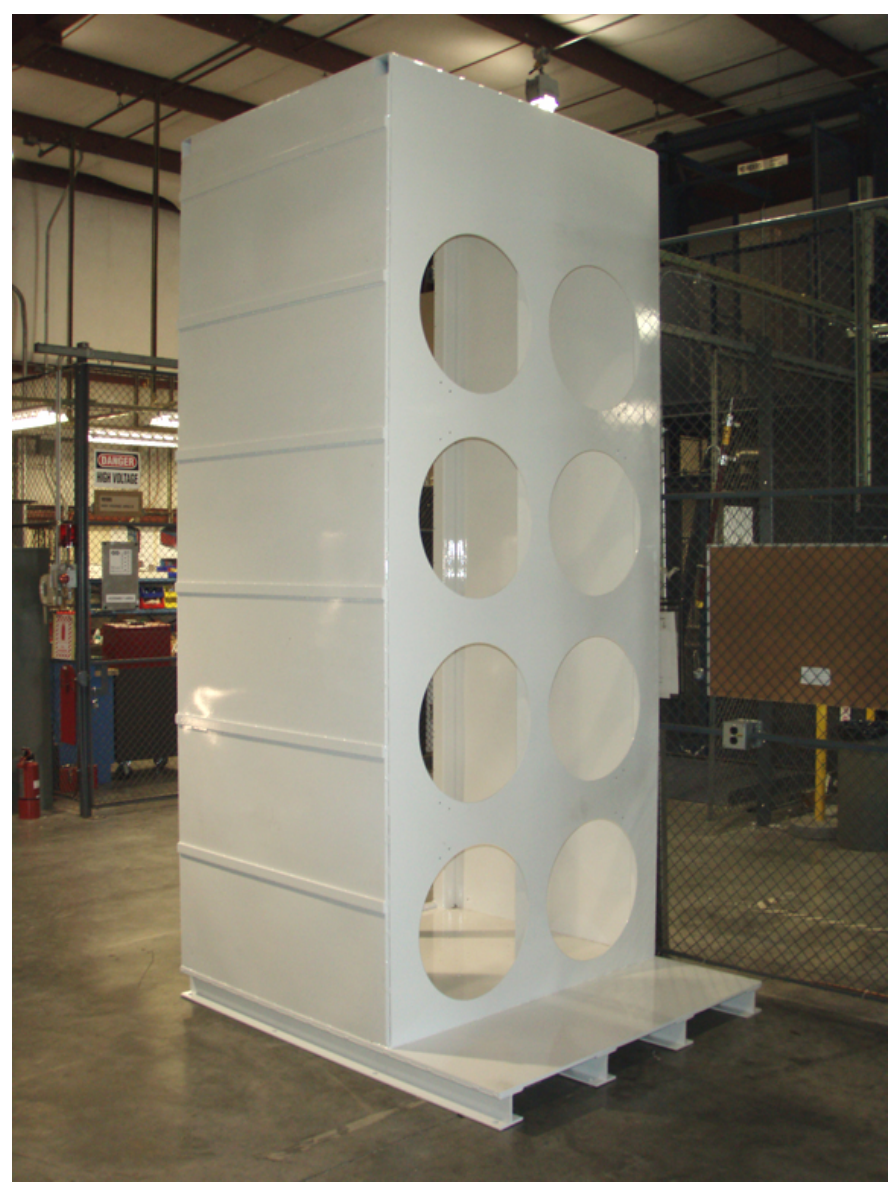

Figure 9. External Casing for the $150 \mathrm{~kW}$ Test Load.

\section{ACKNOWLEDGMENTS}

Piotr Blum, SLAC, for providing superb mechanical CAD work and for the design and construction of the modulator mechanical components and the cell test bench.

Alfred Viceral, SLAC, for setting up production and testing of the IGBT switch modules.

Craig Brooksby, LLNL, for the design of the $150 \mathrm{~kW}$ aircooled test load currently under construction. 